\title{
A globalização e os processos de transnacionalização das políticas educativas ${ }^{1 *}$
}

\author{
Madalena Mendes \\ Doutoranda em Educação - Universidade Lusófona \\ de Humanidades e Tecnologias; Mestre em \\ Ciências da Educação; Investigadora do Centro de \\ Estudos Observatório de Políticas de Educação e \\ Contextos Educativos - Universidade Lusófona de \\ Humanidades e Tecnologias. \\ Lisboa [Portugal] \\ madalena.mendes@netcabo.pt
}

\footnotetext{
* O editor entendeu necessário manter o registro lingüístico original

- em português lusitano - com acentuação, grafia e expressões.
}

A autora apresenta, neste artigo, a influência das redes da globalização no processo de construção das políticas educativas a partir do confronto entre as concepções teórico-interpretativas de John Meyer - Cultural Educacional Mundial Comum - e de Roger Dale - Agenda Globalmente Estruturada. No processo de crescente internacionalização de um país semiperiférico como Portugal, a autora analisa o processo de construção e reconfiguração das políticas educativas e a influência em termos de legitimação e de mandato de organizações internacionais de pendor predominantemente regulatório como a OCDE e a União Europeia. Ao papel da OCDE na transnacionalização do campo educativo, a partir da década de 1960, a autora acrescenta a análise do processo de europeização das políticas educativas em curso no contexto da Comunidade/União Europeia, a partir da década de 1980.

Palavras-chave: Globalização. Políticas educativas.

Transnacionalização. 
[...] local e global estão distantes e próximos, diversos e iguais. As identidades embaralham-se, multiplicam-se. As articulações e as velocidades desterritorializam-se e reterritorializam-se em outros espaços, com outros significados. O mundo tornase mais complexo, mais simples, micro e macro, épico e dramático. (OCTÁviO IANNI, 1995, p. 201).

\section{Introdução: a globalização das políticas educativas}

As políticas educativas podem ser entendidas como processos de construção e reconstrução das relações de poder filiados nas dinâmicas histórico-sociais e económicas. Privilegiando a estreita relação entre política e poder, Santos (2000) encara as políticas educativas e as políticas em geral como redes ou constelações de poderes criadas e recriadas nas relações sociais. Na linha de Freire, Torres (1998) defende o carácter político da educação no pressuposto de que a arena educacional não é politicamente neutra nem tecnicamente objectiva, pelo que as ligações subtis entre educação e poder têm que ser entendidas num quadro alargado de discussão da natureza política do Estado e das múltiplas relações entre Estado, sociedade e educação ${ }^{2}$. Também Teodoro (2001) acentua o carácter do processo de construção social das políticas educativas atravessadas pela complexidade, heterogeneidade e mestiçagem dos meios em que são construídas.

No processo de construção das políticas educativas não podemos deixar de reconhecer a influência das redes da globalização ${ }^{3}$, quer no estabelecimento das agendas políticas, quer na conceptualização e implementação das orientações e medidas políticas. Diversos autores têm chamado a atenção para a crescente internacionalização das políticas educativas, quer por meio do que designam por globalização das políticas educativas (SEIXAS, 2001) quer pela emergência de fenómenos de padronização patentes na semântica discursiva e nas orientações e medidas políticas nacionais (SCHRIEWER, 1996).

A propósito do debate e concepções subjacentes à relação entre educação e globalização na elaboração e implantação das políticas nacionais, temos de trazer à colação o confronto entre duas concepções teórico-interpretativas: Cultura Educacional Mundial Comum (CEMC), desenvolvida por John Meyer e seus colegas da Universidade de Stanford (Califórnia), e Agenda Globalmente Estruturada para a Educação (AGEE), de Roger Dale, a partir de trabalhos recentes sobre economia política internacional.

A primeira perspectiva está construída na base dos modelos universais de educação, Estado e sociedade caracterizados por "[...] padrões de relativo isomorfismo e mudança convergente [...]" (MEYER, 2000, p. 18), conotando, desse modo, uma sociedade internacional constituída por Estados-Nação individuais autónomos. Segundo os defensores dessa abordagem, referidos como "institucionalistas mundiais", as instituições do Estado-Nação e o próprio Estado são modelados por normas, ideologias e culturas universais comuns. Segundo essa teoria, o campo educativo é fértil em demonstrações, seja pela rápida expansão dos sistemas de educação nacionais ou pelo isomorfismo das categorias curriculares em todo o mundo, fenómenos esses que acontecem independentemente das diferenças económicas, políticas e culturais de cada contexto. 
Para a educação, esta abordagem sublinha que longe de serem autonomamente construídas a um nível nacional, as políticas nacionais são em essência pouco mais do que interpretações de versões ou guiões que são informados por, e recebem a sua legitimação de ideologias, valores e culturas de nível mundial. (DALE, 1994, p. 139).

\section{ACEMCbaliza a Organização para Cooperação} e Desenvolvimento Económico (OCDE), a UNESCO e o Banco Mundial como principais actores internacionais na difusão mundial de padrões e modelos estandardizados no plano educativo.

A segunda perspectiva valoriza a construção de uma agenda globalmente estruturada a partir da interface entre a natureza mutável da economia capitalista como força motriz e as releituras, os enquadramentos interpretativos e as mediações dos sistemas educativos nacionais. Neste debate, Dale (1994) e também Cortesãoe Stoer (2001) concordam com o facto de as dimensões cultural e normativa dos processos de globalização serem afectadas primordialmente pela dimensão socioeconómica, isso sem descurar o impacto das influências externas e, simultaneamente, “[...] o reconhecimento de que os enquadramentos interpretativos nacionais são desenvolvidos quer supranacional quer nacionalmente [...]" (CORTESÃO, STOER, 2001, p. 371).

Barroso (2003), a partir da análise de estudos comparados sobre o papel do Estado e sobre os modos de regulação, delimita três traços fundamentais no processo de progressiva internacionalização das políticas:

- o efeito de contaminação - transferência e importação de conceitos, de medidas e de modelos das políticas postas em prática nos países, à escala mundial, com funções de justificação e de legitimação das políticas nacionais;

- o efeito de hibridismo - sobreposição ou mestiçagem de diferentes lógicas, discursos e práticas, o que reforça o carácter ambíguo, compósito e plural das políticas educativas;

- o efeito mosaico - panóplia de medidas avulsas que visam situações e públicos específicos e que raramente atingem, de modo coerente e agregado, a generalidade do sistema político-educativo.

Conforme já salientámos noutro trabalho ${ }^{4}$, o campo educativo enquanto campo de transnacionalização, constrói-se, precisamente, nessa dinâmica fluída e biunívoca de entrosamento e embaralhamento, entre as dinâmicas internacionais e as nacionais, não numa mera soma ou sobreposição de elementos justapostos, mas antes num processo de definição e redefinição constantes que conduz a tradutabilidades, particularismos, singularidades e hibridismos. Partilhamos com Stoer, Cortesão, Correia (2001) o entendimento de que o campo educativo é um campo conflitual construído na interdependência das forças e poderes económicos, sociais e políticos e na confluência entre o local, o nacional e o global.

Situado numa encruzilhada de forças que o transcendem, o campo educativo surge com características afectadas por percursos históricos do contexto em que tem lugar, surge influenciado por interesses e poderes económicos, pelas relações Estado/mercado, por orientações políticas 
e ideológicas, por localizações mais ou menos centrais, e é ainda marcado por influências do global e do local que nele conflituam. (STOER, CORTESÃO, CORREIA, 2001, p. 14).

Esse processo de internacionalização e construção semântica da sociedade mundial (SCHRIEWER, 1997) assente no papel legitimador do "estrangeiro" (PEREYRA, 1990) produz efeitos decisivos, segundo Teodoro (2001, 2003), em três níveis: (i) na normalização das políticas nacionais; (ii) no estabelecimento de uma agenda universalizadora e veiculadora de modelos, de normas e de opções em nível das políticas nacionais, e (iii) na fixação de um mandato ${ }^{5}$ de acordo com a posição dos países no sistema mundial.

No processo de crescente internacionalização de um país semiperiférico ${ }^{6}$ como Portugal, importa analisar o processo de construção e reconfiguração ${ }^{7}$ das políticas educativas e a influência em termos de legitimação e de mandato de organizações internacionais de pendor, predominantemente, regulatório como a OCDE e a União Europeia.

\section{Portugal - um retrato singular}

A partir da década de 1980, as sociedades ocidentais registraram uma intensificação do fenómeno da globalização associada à revitalização do credo neoliberal pela subordinação da vida social, política e cultural aos axiomas da eficácia, da eficiência, da optimização, da flexibilidade e da adaptabilidade. Em termos políticos, importa salientar a revogação do Estado-Nação e a emergência de poderosos mecanismos de regulação transnacional, como o Fundo Monetário Internacional, o Banco Mundial, a OCDE e a Organização Mundial do Comércio, com poder de actuação e influência sobre os Estados nacionais. Santos (2001, p. 50), reconhece "[...] a importância do papel crescente das formas de governo supra estatal, ou seja, das instituições políticas internacionais, das agências financeiras multilaterais, dos blocos político-económicos supranacionais, dos Think Tanks globais."

Nesse contexto, as políticas educativas passam a desempenhar um papel cada vez mais instrumental na modernização das economias e na resposta aos imperativos da competitividade, da modernização e dos processos de inovação.

No campo educativo, muitos países do contexto europeu, tais como Inglaterra, França, Portugal e Finlândia, introduzem processos reformistas ${ }^{8}$ como tónica dominante das políticas educativas nacionais, a partir dos anos de 1980.

Num pano de fundo, dominado pelo "pensamento único" e pelo think tanks assente na teologia do neoliberalismo e nos "dez mandamentos" do Consenso de Washington" ${ }^{\text {- }}$ - Portugal apresenta um retrato singular. Santos (1993, p. 7) diz-nos, precisamente, que "[...] a singularidade do retrato de Portugal reside tão-só na sua pluralidade.” Na configuração das realidades portuguesas, temos de chamar à colação a suspensão da vida democrática de quase meio século (48 anos), de endoutrinação e inculcação de cariz autoritária, autarcista e anticosmopolita; a inscrição recente de Portugal no rol das jovens democracias $\left(3^{\text {a }}\right.$ vaga de democratização de Huntington, com o 25 de Abril de 1974) e o crescente multiculturalismo da sociedade portuguesa, resultante quer do processo de descolonização, quer da intensificação de fenómenos de imigração.

A década de 1980 representa, relativamente a Portugal, um importante ponto de viragem 
e de transição na sociedade portuguesa e na organização estatal, com reflexos em seu processo de recontextualização no sistema mundial, com a adesão à então designada Comunidade Económica Europeia, e nos níveis de exigência em matéria de desenvolvimento e modernização do país. No plano educativo, importa sublinhar a publicação da Lei de Bases do Sistema Educativo, em 1986, a qual serve de pilar à reforma curricular, instituída a partir de 1989, e que se inscreve no propósito mais amplo de reformar e reestruturar a globalidade do sistema marcado por um sintomático atraso educativo patente, entre outros, na democratização escolar tardia, nos baixos índices de escolarização, no abandono escolar precoce, nas elevadas taxas de analfabetismo e na iliteracia (BENAVENTE, ROSA, COSTA, ÁVILA, 1996).

A especificidade típica de um país de condição semiperiférica, com um sistema educativo tradicionalmente centralizado e intra-mural, legitima, em Portugal, o aparecimento de fenómenos híbridos de simultânea crise e consolidação da escola de massas e de processos de expansão e retracção da função providencial do Estado (STOER, ARAÚJO, 1992; ARAÚJO, 1996).

\section{A Europa e a construção de uma agenda globalmente estruturada}

A concessão de empréstimos e o planeamento educacional, a estandardização e a imposição emergiram como algumas das formas pioneiras na construção de uma agenda globalmente estruturada, legitimada pelas teorias da modernização e pelo seu hubris regulatório - as teorias de capital humano -, protagonizadas, sobretudo a partir das décadas de 50 e de 60 do século passado, por organizações internacionais como a OCDE e o Banco Mundial, e o FMI ${ }^{10}$, a partir da década de 1970.

Nos anos 1950 a 1970, é de realçar a forte influência do Ocdeísmo em Portugal, patente na adopção de medidas de política educativa relacionadas com a expansão da escolaridade, com o planeamento educacional e com a modernização administrativa. Apesar de Portugal manter a participação em alguns projectos existentes na OCDE, no período respeitante à fase revolucionária, é de salientar a influência da UNESCO na legitimação do eixo educação-democraciacidadania (STOER, ARAÚJO, 1991) por meio das preocupações acrescidas com a democratização do sistema de ensino. A OCDE volta a assumir papel preponderante nas políticas educativas nacionais, na década de 1980, quando da elaboração da Lei de Bases do Sistema Educativo, ao participar do exame às políticas educativas nacionais. Teodoro (2003) busca alvitrar a hipótese de a agenda globalmente estruturada ter, sobretudo, como centro nevrálgico os grandes projectos estatísticos internacionais, particularmente o Projecto INES do Centre for Educational Research and Innovation da $\mathrm{OCDE}^{11}$. A gestão, a medida e a comparação da performance dos indivíduos, dos sistemas e dos Estados, no seio de uma economia global de mercado, transformaram-se na componente central da governação em educação. Preenchendo um papel normativo e legitimador, o Projecto dos Indicadores, enquanto instrumento das políticas educativas, ilustra a transformação do papel da OCDE. De catalisadora e facilitadora do desenvolvimento das políticas nos Estados Membros, por meio da ajuda aos processos de disseminação, adaptação e empréstimo, a OCDE tem vindo a assumir-se como um media- 
dor internacional da economia do conhecimento e um actor político global (HENRY; LINGARD; RIZVI; TAYLOR, 2001).

Ao papel da OCDE na transnacionalização do campo educativo não podemos deixar de acrescentar o processo "vincado" de europeização das políticas educativas em curso no contexto da Comunidade/União Europeia ${ }^{12}$, sobretudo a partir da década de 1980.

A emergência de múltiplas relações funcionais e de (inter)dependência crescentes entre a elaboração das políticas nacionais e comunitárias e as prioridades e instituições comunitárias evidencia os contornos de um processo crescentemente vincado de "europeização" da educação [...] (ANTUNES, 2006, p. 129, grifo do autor).

Conforme salientámos em anterior trabalho, as políticas educativas, delineadas a partir dos anos de 1980, no contexto da entrada de Portugal na então designada Comunidade Económica Europeia, vão representar a consagração da lógica da modernização como o bubris indispensável à superação do lusitano atraso e, simultaneamente, como o leitmotiv da recontextualização da identidade nacional fortemente abalada pelo processo de descolonização e pelo esgotamento de modelos de cooperação associados à Associação Europeia de Livre Comércio (EFTA), funcionando, desse modo, como verdadeiro motor exógeno do desenvolvimento do país (PETRELLA, 1990). A tónica dominante e legitimadora das políticas educativas, a partir da década de 1980, situa-se no plano da ideologia da modernização, pela referencialização do campo educativo ao mundo empresarial e à definição económica de educação (CORREIA, 1999). A democratização da educação passa a ser justificada e legitimada por imperativos de crescimento económico atento ao renovado interesse no capital humano ${ }^{13}$, expressão reactualizada do paradigma económico dominante nos anos $60 \mathrm{e}$ 70 do século passado.

Numa análise sócio-histórica da racionalidade das políticas educativas de Bruxelas, Nóvoa (1998) identifica três grandes eixos estruturantes: a lógica económica radicada num renovado apelo às teorias de capital humano; o discurso da qualidade patente na ideologia da eficácia e da eficiência, e a retórica da cidadania assente num discurso sobre os valores europeus referenciado ao multiculturalismo e à coesão social. E a propósito deste último referencial, este autor explicita que "[.. .] la démocratie, la tolérance ou la solidarité font partie d'une langage qui légitime les efforts politiques à travers de la construction d'une histoire de l'Europe comme centre éclaire da la civilisation." (NÓVOA, 1998, p. 110). Relativamente à lógica económica, refere que a racionalidade económica serve orientações neoliberais por meio do discurso da privatização, da livre escolha e mesmo da participação.

A Europa funciona como idéal regulatoire (NÓVOA, 1998) das políticas educativas dos Estados membros, projectando, desse modo, “[. . .] um universo imaginário onde Portugal se transforma num país europeu igual aos outros [...]" (SANTOS, 1993, p. 51). O "Estado-como-imaginação-do-centro" é a forma política, encontrada por Santos, para caracterizar o processo português de integração europeia, sinalizando o papel da União Europeia como agente de inculcação social da imaginação do centro, na expressiva frase: estar com a Europa é ser como a Europa. 


\section{A emergência do Estado Competitivo e a reconfiguração dos sistemas educativos}

Nos cenários actuais de erosão da protecção estatal, emergem processos híbridos de combinação entre a regulação estatal, a des-regulação e a re-regulação. Na verdade, os processos de des-regulação assentes em lógicas de descentralização em torno da autonomia, da participação e da responsabilização social acabam por traduzir-se em estratégias de recentralização e de controlo remoto (LIMA, 1994) sobre os resultados do sistema educativo e sobre os actores educativos. O Estado competitivo emerge na sua plenitude, no contexto global, supranacional e local, combinando a política da acumulação com a legitimação e reconfigurando as faces dos sistemas educativos norteados, agora, pela economia do conhecimento, pelos mercados escolares e pela avaliação internacional (DALE, 1988).

Conscientes de que as mudanças dos padrões de regulação no plano global e local estão umbilicadas nas transformações políticas, económicas, sociais e políticas, não podemos deixar de celebrar a importância da teoria crítica ${ }^{14}$ no desvelamento das mistificações ideológicas e das racionalidades instrumentais que caracterizam os processos de transnacionalização das políticas educativas.

\section{The globalization and the process of transnationalization of educational policies}

The author presents, in this article, the influence of the globalization's nets in the process of construction of educational policies from the confrontation between the interpretative-theoretical conceptions developed by John Meyer - Education World-Wide Common Culture (CEMC) - and by Roger Dale -Globally Structured Educational Agenda. In the process of growing internationalization of a semiperipheric country like Portugal, the author analyses the process of construction and reconfiguration of the educational policies and the influence in terms of legitimation and mandate of international organizations of tendency predominantly regulatory feature as OECD and European Union. To the role of OECD in the transnationalization of educational field, from the decade of 1960, the author adds the analysis of the process of europeization of the educational current policies in the context of the European Community/European Union, from the decade of 1980.

Key words: Globalization. Public policies. Transnationalization.

\section{Notas}

1 Artigo produzido no âmbito do Projecto de Investigação "Educating the Global Citizen: Globalization, Educational Reform and the Politics of Equity and Inclusion in 12 Countries. The Portuguese Case”. Este projecto está aprovado e é financiado pela Fundação para a Ciência e Tecnologia (POCI/CED/56992/2004), integrando-se em uma rede internacional coordenada pelo professor doutor Carlos Alberto Torres, da Universidade da Califórnia (UCLA), em Los Angeles.

2 Sobre a tese de que uma teoria crítica do poder e do Estado é um ponto de partida necessário para o estudo da política educativa e de que as relações entre o poder, a organização complexa e o Estado devem ser entendidas a partir da acção 
conjugada ente economia política e sociologia política, ver Morrow e Torres (1997). Nesta obra, os autores propõem que o estudo da elaboração das políticas se faça no registo cruzado de dimensões analíticas distintas, tais como: (i) objectivos do Estado e os alvos das suas políticas; (ii) modos e métodos de funcionamento na elaboração da política educativa, com especial ênfase nos problemas da acumulação de capital e/ou práticas e da legitimação política; (iii) extensão e tipo de racionalidades organizacionais; (iv) ideologias burocráticas; (v) resultados materiais e não materiais das políticas; (vi) unidades capitalistas e não-capitalistas de elaboração de políticas; (vii) papel da política educativa no contexto da política global; (viii) lutas e acções contra-hegemónicas. Ver também Torres (2005).

3 A globalização pode ser entendida como o processo, sem precedentes, de intensificação das relações económicas, sociais, políticas e culturais em escala mundial. Esse processo de desenvolvimento desigual que fragmenta à medida que coordena (GIDDENS, 2000) é considerado por Santos (2001), na riqueza e complexidade de sua pluralidade, porquanto a(s) globalização(ões) inclui(em) diferentes conjuntos de relações sociais conflituais entre Estados, grupos sociais e interesses hegemónicos e contra-hegemónicos.

4 Ver Mendes, 2004.

5 Mandatos para o sistema educativo “[. . . ] são concepções sobre o que o sistema deve realizar a partir do que é definido como desejável e legítimo. Em qualquer momento existem numerosos 'mandatos' atribuindo diferentes prioridades às três mais importantes categorias de metas a serem alcançadas pelo sistema educativo: i) o autodesenvolvimento; ii) a cidadania; iii) a formação" (DALE, 1989, p. 66).

6 Wallerstein (1994) é um dos representantes das teses sociológicas mais influentes que consideram o mundo como um único sistema, constituído por Estados centrais (de forte estrutura governamental, desenvolvidos e ricos), Estados periféricos (fraca estrutura governamental, culturas dominadas) e Estados semiperiféricos (países com estruturas governativas relativamente fortes e economias, de alguma forma, dependentes dos Estados centrais).

7 Magalhães e Stoer (2006), acentuando o plural, reconhecem que estamos na presença de um amplo processo de reconfiguração das estruturas sociais, económicas e políticas com reflexos paradigmáticos ao nível da educação, da cidadania e da formação das identidades individuais e colectivas.

8 Hirtt (2001) estabelece a ligação estreita entre as demandas da economia capitalista global e o conteúdo das reformas educativas por meio dos sucessivos apelos a “[...] descentralização, desregulamentações, autonomia crescente dos estabelecimentos escolares, reduções dos programas, abordagem das competências [...] parcerias com o mundo do trabalho, introdução maciça das tecnologias da informação e da comunicação (TIC), incentivo ao ensino privado e público [...]"( p. 1).

9 Os dez mandamentos são: disciplina fiscal, prioridades na despesa pública, reforma fiscal, liberalização financeira, câmbio de mercado, taxas de câmbio, investimento estrangeiro directo, privatização, desregulação e direitos de propriedade.

10 A negociação e aplicação do Primeiro Programa de Estabilização patrocinado pelo FMI, no período 1977/1979, implicou a adopção de um conjunto de medidas de política económica que visavam, essencialmente, à redução do investimento e das despesas públicas e à do consumo privado.

11 O Projecto Internacional sobre os Indicadores em educação tem-se tornado parte significativa do trabalho desenvolvido no seio da OCDE. Os indicadores ajudam os Estados-membros a clarificar e a comparar o posicionamento no âmbito das políticas e, simultaneamente, 
escalonam os países num ranking comparativo em torno de assunções sobre provisão e performance.

Nessas novas formas de governação, os indicadores de performance servem aos mecanismos da accountability e legitimam a agenda neoliberal da educação e a sua ênfase na mercadorização dos sistemas educativos.

12 A educação esteve ausente desta organização durante algumas décadas, atento ao seu cariz inicialmente económico. Só a partir da década de 1980, sobretudo a partir do Tratado de Maastricht (1992) é que se assistiu à progressiva institucionalização e consolidação da educação como área de cooperação entre os Estadosmembros.

13 A acentuação da relação biunívoca entre educação e desenvolvimento económico, social e político das sociedades sofreu forte incremento na década de 60 do século XX, com a generalização das teorias do capital humano, de que Shultz $(1963,1971)$ é considerado um dos pioneiros clássicos.

14 Sobre esta temática, aliada à necessidade de construção de uma cultura de resistência e de uma linguagem das possibilidades ante as múltiplas faces da globalização. (Ver Torres, 2005).

\section{Referências}

ANTUNES; F. A europeização das políticas educativas: a nova arquitectura e o novo elenco no campo da educação. In: MAGALHÃES, A.; STOER, S. R. Reconfigurações. Educação, Estado e Cultura numa época de Globalização. Porto: Profedições/ Jornal a Página da Educação, p. 129-137, 2006.

ARAÚJO, H. C. Precocidade e retórica da escola de massas em Portugal. Educação, Sociedade e Culturas, n. 5, p. 161-174, 1996.
BARRoso, J. (Org.). A escola pública - Regulação, desregulação e privatização. Porto: Edições Asa, 2003.

BEnAVEnTE, A.; ROSA, A.; COSTA A. F.; ÁVILA, P. A literacia em Portugal. Resultados de uma pesquisa extensiva e monográfica. Lisboa: Fundação Calouste Gulbenkian / Conselho Nacional de Educação, 1996.

CORREIA; J. A. As ideologias educativas em Portugal nos últimos 25 Anos. Revista Portuguesa de Educação, 12 (1), 81-110, 1999.

CORTESÃO, L.; STOER, S. Cartografando a transnacionalização do campo educativo: o caso português. In: SANTOS, B. S. (Org.). Globalização fatalidade ou utopia? Porto: Afrontamento, p. 370406, 2001.

DALE, R. A educação e o Estado capitalista: contribuições e contradições. Educação $e$ Realidade, v.13, p. 1, p. 17-37, 1988.

The State and education policy. Milton Keynes, Philadelphia: Open University Press, 1989. - A promoção do mercado educacional e a polarização da educação. Educação, Sociedade e Culturas, n. 2, p. 109-139, 1994.

GIDDENS, A. O mundo na era da globalização. Lisboa: Editorial Presença, 2000.

HENRY, M.; LINGARD, B.; RIZVI, F.; TAYLOR, S. The OECD, Globalisation and Education Policy. Oxford: Pergamon Press, 2001.

HIRTT, N. Os sistemas educativos na época da globalização liberal: rumo à escola "mercantilizada". Comunicação apresentada no Fórum Mundial de Educação, Porto Alegre, Brasil, 24 a 27 de Outubro de 2001. Disponível em: $<$ http://www.portoalegre.rs.gov.br/fme/up_arquivo// Nico\%20Hirtt.pdf $>$. 
IANNI, O. Teorias da globalização. Rio de Janeiro: Civilização, 1995.

LIMA, L. Modernização, racionalização e optimização. Perspectivas neo-taylorianas na organização e administração da educação. Cadernos de Ciências Sociais, n. 14, p. 119-139, 1994.

MAGALHÃES, A; STOER, S. (Org.). Reconfigurações. Educação, Estado e cultura numa época de globalização. Porto: Profedições, 2006.

MENDES, M. As faces de Janus. As políticas educativas em matéria de cidadania nos anos 90 em Portugal. Dissertação (Mestrado em Educação)- Programa de Mestrado em Ciências da Educação. Universidade Lusófona de Humanidades e Tecnologias, Lisboa, 2004.

MEYER, J. W. Globalização e currículo. Problemas para a Teoria em Sociologia da Educação. In: NÓVOA, A.; SCHRIEWER, J. (Ed.) A difusão mundial da escola. Lisboa: Educa, 2000. p. 15-32.

MORROW, R; TORRES, C. A. Teoria social e educação. Uma crítica das teorias da reprodução social e cultural. Porto: Afrontamento, 1997.

PEREYRA, M. A. La comparación, una empresa razonada de análisis. Por otros usos de la comparación. Extraordinario: Los usos de la comparación en Ciencias Sociales y Educación. Revista de Educación, p. 23-76, 1990.

PETRELLA, R. Reflexão sobre o futuro de Portugal (e da Europa). Prefácio e tradução de Manuela Silva. Lisboa: Gulbenkian, 1990. (VII Vol. Portugal, os próximos 20 anos).

NÓVOA, A. Histoire E Comparaison (Essais sur l'Éducation). Lisboa: Educa, 1998.
SANTOS, B. S.(Org.). Portugal: um retrato singular. Porto. Afrontamento / Centro de Estudos Sociais, 1993.

. A crítica da razão indolente. Contra o desperdício da experiência. Porto: Edições, 2000. . (Org.). Globalização. Fatalidade ou utopia? Porto: Afrontamento, 2001.

SEIXAS, A. M. Políticas educativas para o ensino superior: a globalização neoliberal e a emergência de novas formas de regulação estatal. In: STOER, S. R.; CORTESÃO, L.; CORREIA, J. A. (Org.). Transnacionalização da educação: da crise da educação à "educação" da crise. Porto: Afrontamento, 2001. p. 209-238,

SCHRIEWER, J. Sistema Mundial y Redes de Interrelación: La internacionalización de la educación y el papel de la investigación comparada. In: PEREYRA, M. A.; MÍNGUEZ, J. G.; BEAS, M.; GÓMEZ, A. J. (Org.). Globalización y descentralización de los sistemas educativos. Barcelona: Pomares-Corredor, 1996. p. 17-58. . L'éducation comparée: mise en perspective historique d'un champ de recherche. Révue Française de Pédagogie, n. 121, p. 9-27, 1997.

SCHULTZ, T. W. The economic value of education. Nova Iorque: The Free Press, 1963. Investment in buman capital. The role of education and research. Nova Iorque: The Free Press, 1971.

STOER, S. R.; ARAÚJO, H. C. Educação e democracia num país semiperiférico (no contexto europeu). In: STOER, S. R. (Org.). Educação, ciências sociais e realidade portuguesa. Uma abordagem interdisciplinar. Lisboa: Editorial Fragmentos, 1991. p. 205-230.

Dialogia, São Paulo, v. 6, p. 107-117, 2007. 
STOER, S. R.; ARAÚJO, H. C. Escola e aprendizagem para o trabalho num país da semi-periferia europeia. Lisboa: Escher, 1992.

STOER, S. R., CORTESÃO, L.; CORREIA, J. A. (Org.). Transnacionalização da educação. Da crise da educação à "educação" da crise. Porto: Afrontamento, 2001.

TEODORO, A. A construção política da educação. Estado, mudança social e políticas educativas no Portugal contemporâneo. Porto: Afrontamento, 2001.

Globalização e educação. Políticas

educacionais e novos modos de governação. São Paulo: Cortez, 2003.
TORRES, C. A. Democracy, Education and Multiculturalism. Dilemmas of Citizenship in a Global World. Maryland: Rowman \& Littlefield Publishers, 1998.

Os mundos distorcidos de Ivan Illich e Paulo Freire. In: TEODORO, A.; TORRES, C. A. Educação crítica e utopia. Perspectivas para o século XXI. Porto: Edições Afrontamento, 2005. p. 83-100.

WALLERSTEIN, I. O sistema mundial moderno. Vol. II . O mercantilismo e a consolidação da economia-mundo-europeia, 1600-1750. Porto: Afrontamento 1994. (Ed. or. 1980). recebido em 11 set. 2007 / aprovado em 10 out. 2007

Para referenciar este texto:

MENDES, M. A globalização e os processos de transnacionalização das políticas educativas. Dialogia, São Paulo, v. 6, p. XX-XX, 2007. 
